\title{
SHORT NOTE: HOW TO MAKE FERTILISER BALLS FOR AQUATIC PLANTS
}

\section{Pat Clifford ${ }^{6}$}

The Royal Botanic Garden Edinburgh (RBGE) cultivates a wide variety of tropical aquatic plants, most of which are growing in the Plants and People display glasshouse. Here, many of the economically important tropical crop plants such as coffee, cocoa and rice are displayed along with ornamental species and, in the large pond, aquatic plants (Fig. 1). The most notable of these are the giant water lilies, the species Victoria amazonica and V. cruziana, and their biology and cultivation described in Clifford (2005). Like other cultivated plants they require fertiliser to be vigorous and healthy, and over the years a method for making fertiliser balls has been developed which is both cost-effective and simple to adjust for different species' requirements.

Species and cultivars in the genus Victoria are referred to as 'victorias'. When growing these plants it is essential to understand their nutrient requirements. Victorias are notoriously 'heavy feeders' and therefore need plenty of nitrogen, which fuels the growth of their massive leaves. Seeds are sown in January and repotted in stages into containers; the container for the last stage is 300 litres in capacity. These are lowered into the pond in April and removed in November or December, when growth has stopped and their appearance has deteriorated. In Scotland at the height of summer the leaves can easily exceed $2 \mathrm{~m}$ in diameter and to facilitate this growth they are fed with fertiliser balls made at the beginning of the growing season. In 2012 Victoria amazonica, V. cruziana and the hybrid between the two, the stunning Victoria 'Longwood Hybrid', will be planted.

\section{METHOD}

To make the fertiliser balls take a general instant-release inorganic fertiliser with the NPK (nitrogen, phosphorus, potassium) ratio of 2:1:1 and add this to some heavy soil which is low in organic matter, obtained from the garden or loam stack at a ratio of four parts soil to one part fertiliser. This should be thoroughly chopped and mixed together, with a little water added to achieve a 'claggy' and sticky consistency.

Wearing disposable gloves, fashion the mixture into tennis ball shapes and lay them out on a polythene sheet to dry (Fig. 2). The reason for using poor soil in the mixture is because if soil has too much organic matter the balls will not set hard and will break up when pushed into the container. The containers are fed every 10 days throughout the growing season by pushing the balls into the pot down the side of the root ball. As the

6. Pat Clifford is a Senior Horticulturist at the Royal Botanic Garden Edinburgh, specialising in the cultivation of tropical plants.

Address: 20A Inverleith Row, Edinburgh EH3 5LR.

Email: P.Clifford@ rbge.org.uk 


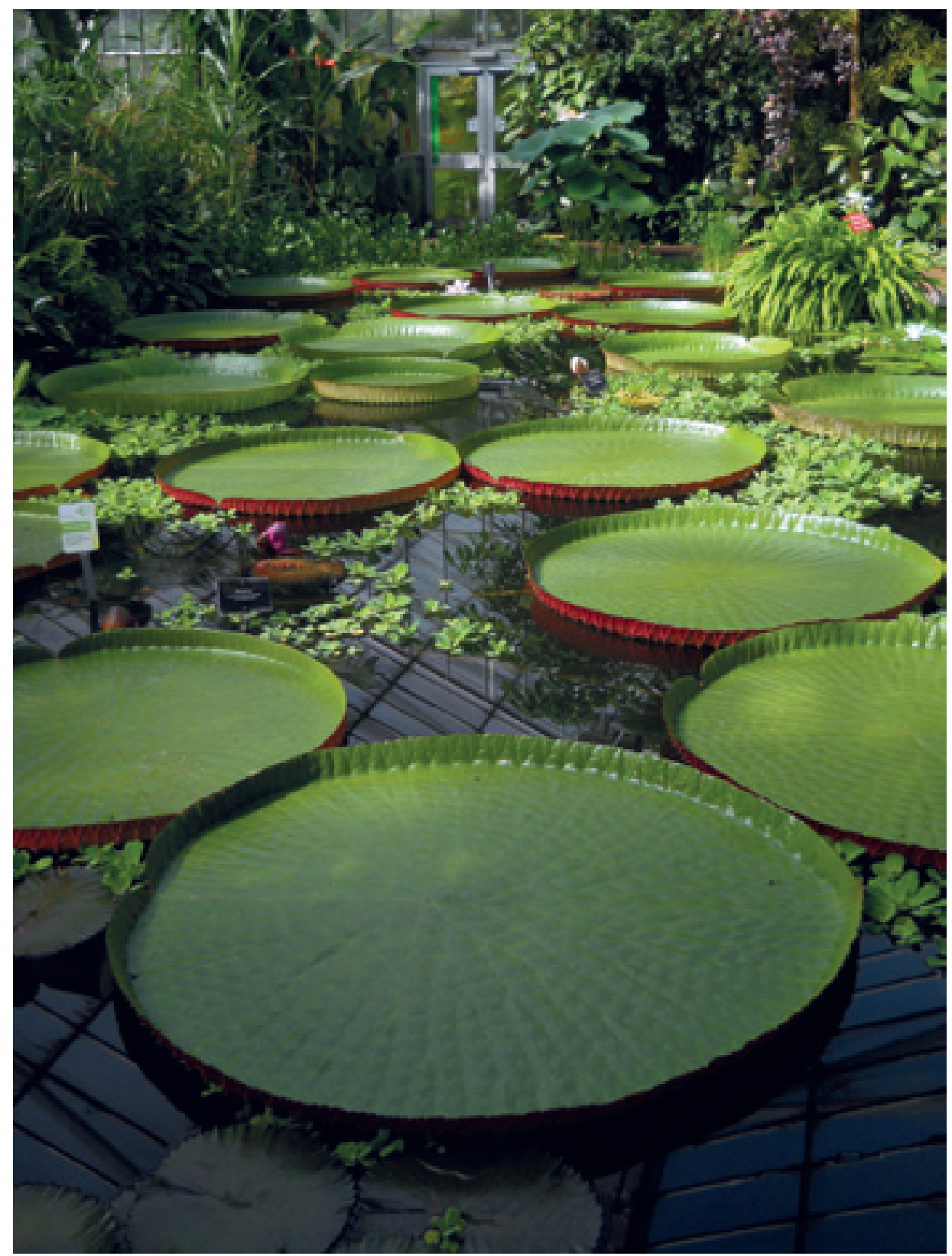

Fig. 1 The Plants and People display glasshouse and pond with Victoria 'Longwood Hybrid' in the foreground with a red underside to the lip of the leaf. Victoria cruziana is in the middle of the pond with a green lip which is higher than the cultivar. Photo: David Knott. 


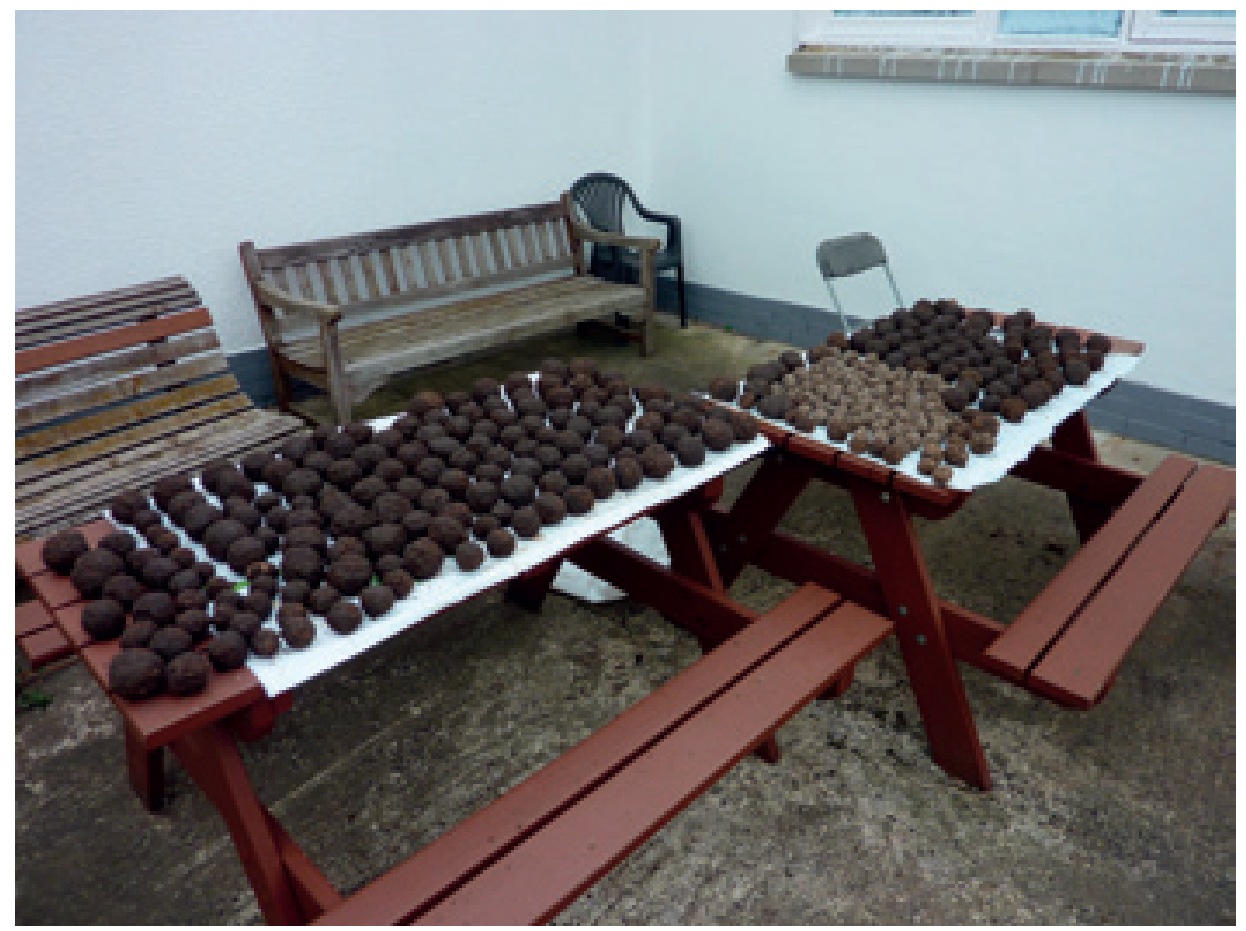

Fig. 2 Fertiliser balls drying in the open air in April. Photo: Pat Clifford.

balls slowly break down they supply the plant with a constant flow of nitrogen. Five balls are inserted per pot.

\section{Adapting the basic recipe}

Nymphaea cultivars such as 'Texas Shell Pink', 'Pamela' (Fig. 3) and 'St Louis Gold' (Fig. 4) are also planted in the pond. These plants are overwintered as tubers kept in the tropical back-up glasshouse and are reintroduced into the Plants and People glasshouse in early March. They flower profusely from April to November every year, and the purpose of feeding the plants is to encourage flower production instead of leaves. To make fertiliser balls for Nymphea sp. the same procedure is followed but using a high potassium fertiliser with a ratio of 1:1:2. The balls made are smaller than for the victorias (about half the size) and three balls are inserted into each pot every twenty-one days between April and November.

These fertiliser balls give wonderful results and year after year the pond is as popular and well-loved by staff and visitors as ever. 


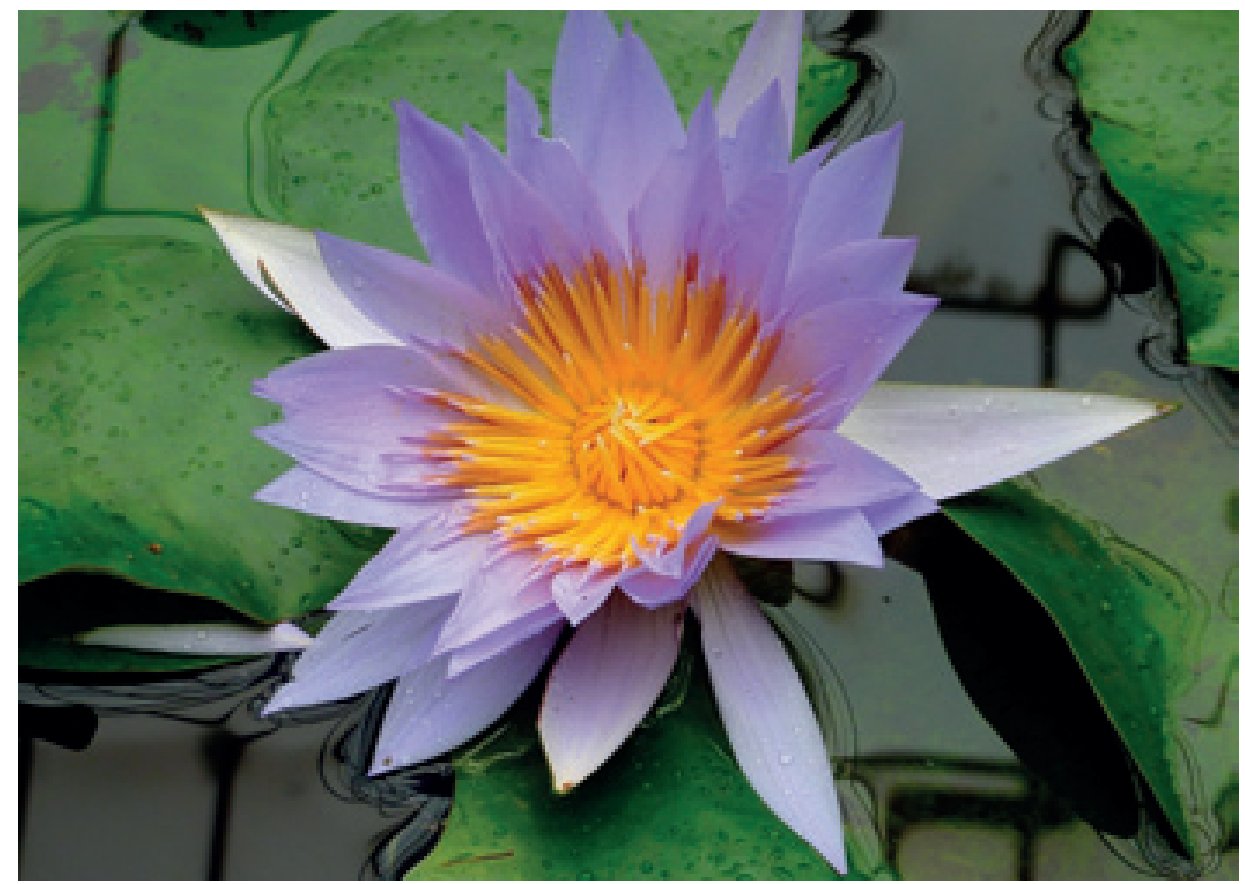

Fig. 3 Nymphaea 'Pamela'. Photo: Pat Clifford.

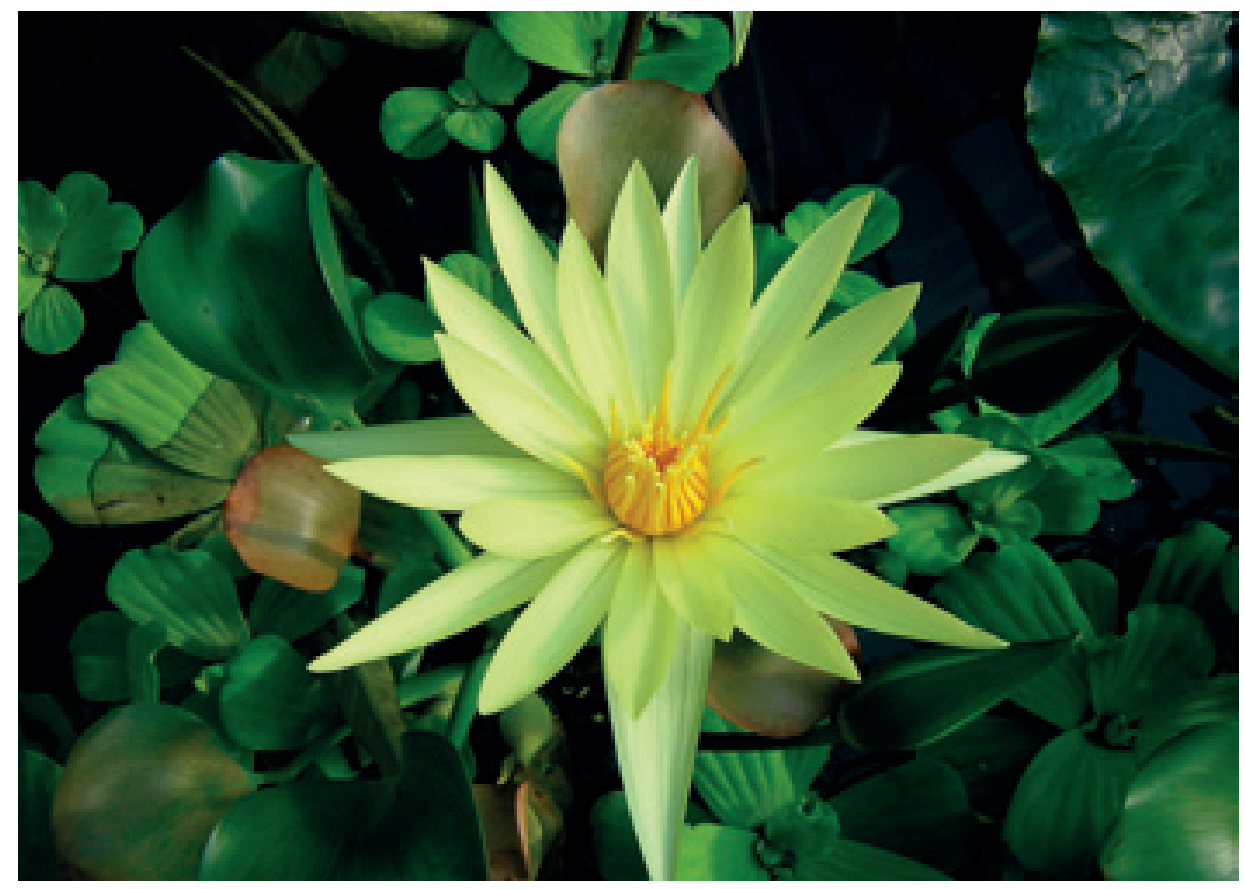

Fig. 4 Nymphaea 'St Louis Gold'. Photo: Pat Clifford. 


\section{REFERENCE}

CLIFFORD, P. (2005). The cultivation of Victoria amazonica Sowerby in northern latitudes. Sibbaldia, 3, 59-66. 